\title{
Prenatal Dexamethasone and Exogenous Surfactant Therapy: Surface Activity and Surfactant Components in Airway Specimens
}

\author{
M. A. KARI, T. AKINO, AND M. HALLMAN \\ From the Children's Hospital, University of Helsinki, Helsinki, Finland [M.A.K.], Department of \\ Biochemistry, Sapporo Medical College, Sapporo, Japan [T.A.], and Department of Pediatrics, University \\ of California, Irvine, California 92717 [M.H.]
}

\begin{abstract}
To explain some of the effects of prenatal glucocorticoid treatment on lung function, surfactant parameters in the airway specimens of ventilator-dependent preterm infants were analyzed. In this double-blind study, the mothers of these infants had received dexamethasone (DEX) or placebo prenatally. Human surfactant was given for the treatment of moderate to severe respiratory distress syndrome. Seventy-six preterm infants with mean gestational age of $29 \mathrm{wk}$ and mean birth weight of $1137 \mathrm{~g}$ were studied. The concentrations of surfactant components in epithelial lining fluid (ELF) were analyzed, and the surface activity was measured using a pulsating bubble method. Prenatal DEX treatment increased the responsiveness to exogenous surfactant and decreased the severity of respiratory failure during the first day of life. The treatment had no effect on the concentrations of surfactant phospholipids that were generally high. Prenatal DEX treatment increased the association between phospholipid concentration in ELF and the degree of respiratory failure. Prenatal DEX improved the surface activity of surfactant isolated from airway specimens and tended to increase the ratio of surfactant protein A to phosphatidylcholine among recipients of exogenous surfactant. A subgroup of infants, offspring of
\end{abstract}

\section{ABSTRACT}

mothers with severe hypertension had an abnormally low concentration of surfactant protein A and a poor outcome, despite prenatal DEX treatment or surfactant substitution. Prenatal DEX decreased the concentration of nonsedimentable proteins in ELF and decreased the inhibition of surface activity by these proteins. Our results indicate that improved surfactant function during the first day of life explains some of the beneficial pulmonary effects of prenatal glucocorticoid treatment in preterm infants who are ventilator-dependent. (Pediatr Res 38: 676-684, 1995)
AS, airway specimen
Abbreviations
CLD, chronic lung disease
DEX, dexamethasone
ELF, epithelial lining fluid
$\mathrm{Fio}_{2}$, fractional inspiratory oxygen
MAP, mean airway pressure
PC, phosphatidylcholine
PL, placebo
RDS, respiratory distress syndrome
SP-A, surfactant protein A

Several randomized studies have shown that prenatal glucocorticoid treatment before preterm delivery improves survival and decreases the incidence of RDS in preterm infants (1). Likewise, treatment with both natural and synthetic surfactants decreases the mortality of very low birth weight infants and the severity of RDS (2). In newborn infants with RDS, exogenous surfactant therapy improves gas exchange, functional recidual capacity, and dynamic compliance (3). A retrospective analysis of surfactant trials suggests that the combination therapy of prenatal glucocorticoid and exogenous

Received December 27, 1994; accepted May 9, 1995.

Correspondence: Anneli Kari, M.D., Children's Hospital, University of Helsinki, Stenbäckinkatu 11, FIN-00290 Helsinki, Finland.

Supported by the Foundation of Pediatrics Research, Finland, and the Foundation for Maternal and Infant Care, Orange County, CA. surfactant has a favorable additive effect on gas exchange and on the requirement of ventilatory pressures (4).

In animal experiments, glucocorticoids increase lung aeration (5), decrease surface tension of the lung extract (6), and increase synthesis of surfactant phospholipids and surfactant proteins (7). In ventilated animals, prenatal glucocorticoid treatment further alters the composition of the connective tissue in the lung $(8,9)$ without consistently increasing the alveolar pool of surfactant phospholipids (8-13). In studies involving preterm rabbits, reduction in the protein leak and improvement in the pulmonary function suggest that a favorable interaction exists between prenatal glucocorticoid and exogenous surfactant therapy $(10,11)$.

The mechanisms explaining the beneficial effects of the combination of prenatal glucocorticoid and exogenous surfactant therapy on pulmonary morbidity in preterm infants are 
insufficiently known. According to a randomized multicenter study, prenatal DEX treatment improved the outcome of the preterm infants when exogenous surfactant is available (14). The aims of the present study were to investigate how prenatal glucocorticoid treatment influences the acute efficacy of surfactant therapy, how prenatal glucocorticoid treatment influences the surface activity of the endogenous surfactant complex and the concentrations of surfactant components in the ELF, and whether the surfactant indices correlate with the degree of respiratory failure.

\section{METHODS}

Patients. The 76 study infants were treated at the Children's Hospital, University of Helsinki, between April 1989 and November 1991. The study infants and their mothers came from a single center and participated in the multicenter trial of prenatal DEX and exogenous human surfactant treatment (14). Altogether 112 pregnant women were enrolled at the Departments I and II of Obstetrics and Gynecology, University of Helsinki. These women delivered 138 live-born infants. Of these 138 infants, 80 [DEX 46, placebo (PL) 34] infants of 24-34 wk of gestation without life-threatening malformations required ventilatory support. Thirty-one (DEX 18, PL 13) infants born at 24-34 wk did not require ventilatory support. Four of the 80 infants (DEX 3, PL 1) received only a short period of ventilatory support, and no aspirates are available. Thus, tracheal aspirates from 76 infants were analyzed.

Pregnant women were eligible for the study if they fulfilled the entry criteria: 1 ) threatened preterm delivery between 24.0 and 31.9 wk of gestation, 2) intact fetal membranes, and 3) absence of chorioamnionitis, congenital fetal anomaly, or documented fetal lung maturity. After obtaining written informed consent, eligible pregnant women were blindly and randomly allocated to receive either DEX or PL intramuscularly. The pregnant women in the DEX group received $6 \mathrm{mg}$ of DEX sodium phosphate (Oradexon, Organon, Oss, The Netherlands), and those in the PL group received $0.9 \%$ saline, four doses at 12 -h intervals over $36 \mathrm{~h}$ if the delivery did not take place. The treatment was not repeated. The investigators and those who provided care were unaware of the prenatal treatment allocation. The study design was approved by the ethical committees of the Children's Hospital and the Departments I and II of Obstetrics and Gynecology, University of Helsinki.

Surfactant therapy and management of respiratory failure. Human surfactant containing all three surfactant proteins (A, $\mathrm{B}$, and $\mathrm{C}$ ) was isolated from amniotic fluid (15), and its sterility was documented as previously described (16). Exogenous surfactant was administered to those infants who fulfilled the following criteria: 1) gestational age $24.0-33.0 \mathrm{wk}$; 2) postnatal age $2-24 \mathrm{~h}$; and 3 ) requirement of mechanical ventilation and at least $40 \%$ oxygen for the treatment of RDS. Retreatment was permitted at a minimum of $2 \mathrm{~h}$ after the first dose if the infant continued to require mechanical ventilation and at least $40 \%$ oxygen. The dose of surfactant was $90 \mathrm{mg}$ in $3.0 \mathrm{~mL}$ of $0.9 \%$ sodium chloride. Up to four doses were permitted within 80 h after birth (14).
For all infants, supplemental oxygen was adjusted to maintain the arterial or transcutaneous oxygen tension within 6.5$9.1 \mathrm{kPa}(50-70 \mathrm{~mm} \mathrm{Hg})$; or oxygen saturation of $\mathrm{Hb}$ within $88-92 \%$, and arterial or capillary $\mathrm{PCO}_{2}$ between $5.8-7.8 \mathrm{kPa}$ (45-60 mm Hg). Ventilatory support was provided with a pressure-limited ventilator (Baby-Bird, Bird Corporation, Palm Springs, CA).

RDS was defined as follows: typical radiographic changes (17), requirement of supplemental oxygen for at least $48 \mathrm{~h}$, and immature surfactant profile in the tracheal aspirate (low lecithin to sphingomyelin ratio and undetectable phosphatidylglycerol). The radiographic severity of RDS in the chest radiographs taken by the age of $12 \mathrm{~h}$ was graded from 1 to 5 (17). In surfactant-treated infants, the severity of RDS was evaluated in the chest radiographs before surfactant administration. If no signs of RDS were detectable, it was scored as 0 . Infants were evaluated for CLD at the age of $28 \mathrm{~d}$. CLD was defined as the requirement of supplemental oxygen. Severe CLD was defined as the requirement of mechanical ventilation and supplemental oxygen. During the $72 \mathrm{~h}$ after birth, the ventilatory parameters and $\mathrm{FiO}_{2}$ requirement were recorded prospectively at 2, 6, 12, $24,36,48$, and $72 \mathrm{~h}$. Similarly, ventilatory parameters and the requirement of $\mathrm{FiO}_{2}$ in surfactant-treated infants were recorded before and after surfactant administration. Severity of respiratory failure was measured using the following index: mean airway pressure $\times \mathrm{FiO}_{2}\left(\mathrm{MAP} \mathrm{cm} \mathrm{H}_{2} \mathrm{O} \times \mathrm{Fio}_{2}\right)$.

Collection of airway specimen. During the first week of life, tracheal aspirates from the intubated infants were obtained daily at 24-h intervals when suctioning was deemed necessary by the nursing staff. The fixed time point of the aspirate collection was considered unethical. The first aspirate collected within an hour after birth was used for the semiquantitative measurement of the lecithin to sphingomyelin ratio and phosphatidylglycerol. Before suctioning of the aspirate, $0.9 \%$ saline $(0.5-1.0 \mathrm{~mL})$ was instilled into the intubation tube, and the infant was ventilated for a brief period. A catheter was then introduced into the airway, distal to the tip of the endotracheal tube. Any fluid in the airways was suctioned into a mucus extractor (UnoPlast AS, Hundested, Denmark) within less than $20 \mathrm{~s}$ after the introduction of saline into the airways. After the procedure, $0.5-1.0 \mathrm{~mL}$ of saline was suctioned through the catheter into the mucus extractor, to recover material retained on the side walls. Aspirates containing visible blood were not analyzed. If the aspirate contained no particles, another aspirate was recovered, and the two aspirates were combined. The specimens were stored for a maximum of $12 \mathrm{~h}$ at $4^{\circ} \mathrm{C}$ and centrifuged at $150 \times g$ for $10 \mathrm{~min}$. The resulting supernatant, called AS, was recovered and stored at $-20^{\circ} \mathrm{C}$.

Measurements of albumin, proteins, phospholipids, and surface tension. SP-A was quantified in AS using a two-site immunoassay with two different MAb (18). Total nonsedimentable protein was measured by a modified Lowry method (19). Albumin was measured with a single radial immunodiffusion using LC-Partigen and VLC-Partigen (Behringwerke AG, Marburg, Germany). The concentration of PC and saturated PC in AS was measured as described elsewhere (20). The lecithin to sphingomyelin ratio and phosphatidylglycerol were isolated by a two-dimensional thin-layer chromatography and 
quantitated by planimetry (21). The molecular weight distribution of the nonsedimentable protein fraction was analyzed using gel electrophoresis. Protein electrophoresis was performed in $10 \%$ SDS-polyacrylamide gel under nonreducing conditions.

The measurements of surface tension were performed at $37^{\circ} \mathrm{C}$ in humidified air in $150 \mathrm{mmol} / \mathrm{L} \mathrm{NaCl}, 1.5 \mathrm{mmol} / \mathrm{L}$ $\mathrm{CaCl}_{2}$, and $10 \mathrm{mmol} / \mathrm{L}$ Tris- $\mathrm{Cl}$ ( $\mathrm{pH} \mathrm{7.4).} \mathrm{The} \mathrm{pulsating} \mathrm{bubble}$ surfactometer was used (22). The bubble radius of $0.40 \mathrm{~mm}$ was maintained for $15 \mathrm{~s}$. Thereafter, the radius was varied between 0.40 and $0.55 \mathrm{~mm}$ at a frequency of $0.33 \mathrm{~Hz}$ for $5 \mathrm{~min}$. The pressure difference $(\Delta \mathrm{P})$ across the surface was continuously recorded. The minimum surface tension $\left(\gamma_{\min }\right)$, i.e. the surface tension at a minimum bubble radius was calculated according to the law of Young and LaPlace: $\Delta \mathrm{P}=2 \times$ $\gamma /$ radius. The rate of surface adsorption was estimated as follows: the bubble, radius $0.40 \mathrm{~mm}$, was created and maintained while the surface tension was recorded. The rate of surface adsorption illustrates the decrease of surface tension from $71 \mathrm{mN} / \mathrm{m}$ toward equilibrium surface tension. Surface tension attained $1 \mathrm{~s}$ after formation of the bubble was reported. The so-called equilibrium surface tension reported is surface tension reached $5 \mathrm{~min}$ after formation of the bubble.

Tracheal aspirates were studied for their components and their capacity to decrease surface activity. The surfactant rich fraction was isolated by centrifugation $(16000 \times g$ during 60 min). The pellet was suspended to $150 \mathrm{mmol} / \mathrm{L} \mathrm{NaCl}, 1.5$ $\mathrm{mmol} / \mathrm{L} \mathrm{CaCl}, 10 \mathrm{mmol} / \mathrm{L}$ Tris- $\mathrm{Cl}(\mathrm{pH} \mathrm{7.4)}$ and washed by centrifugation. The concentration of $\mathrm{PC}$ in the sedimentable fraction was adjusted to $2 \mu \mathrm{mol} / \mathrm{mL}$. For the measurement of the surfactant inhibitor, the nonsedimentable fraction was isolated as follows: supernatant obtained after the sedimentation of the surfactant fraction was recovered. To remove the small particles of surfactant, the supernatant was further centrifuged (40000 $\times g$ during $120 \mathrm{~min}$ ). The new supernatant, called nonsedimentable fraction, was concentrated using a Centricon 3 microconcentrator (cutoff $3 \mathrm{kD}$; Amicon, Beverly, MA). The concentration of protein in the nonsedimentable fraction was adjusted to a final concentration of $4 \mathrm{~g} / \mathrm{L}$ by adding 150 $\mathrm{mmol} / \mathrm{L} \mathrm{NaCl}, 1.5 \mathrm{mmol} / \mathrm{L} \mathrm{CaCl}, 10 \mathrm{mmol} / \mathrm{L}$ Tris-Cl $(\mathrm{pH}$ 7.4). Thereafter, the nonsedimentable protein fraction was added to human surfactant isolated from amniotic fluid (15) to a final PC concentration of $1.8 \mathrm{mmol} / \mathrm{L}$, and the specimen was incubated for $10 \mathrm{~min}$ at $37^{\circ} \mathrm{C}$ before measurement of surface activity. All surface tension measurements were performed in duplicate.

Measurement of the concentrations in the epithelial lining fluid. The concentrations of PC, SPC, SP-A, nonsedimentable protein, and nonsedimentable albumin in ELF were calculated using urea as a marker of the extracellular space $(20,23)$. Urea was quantified in plasma (recovered within $24 \mathrm{~h}$ from the AS) and in the nonsedimentable fraction of AS using an enzymatic method (Unimate5 urea, Roche, Basel, Switzerland). The concentration of PC was calculated as follows: $[\mathrm{PC}]_{\mathrm{ELF}}=[\mathrm{PC}]_{\mathrm{AS}}$ $\times$ urea $_{\text {serum }} /$ urea $_{\mathrm{AS}}$. Uncorrected value of PC is presented as $[\mathrm{PC}]_{\mathrm{AS}}$ that corrected for ELF as $[\mathrm{PC}]_{\mathrm{ELF}}$. Ratios of albumin in ELF to albumin in serum are presented for neonates from whom serum samples were recovered within $24 \mathrm{~h}$ from the AS.
The measurements were validated. Study of preterm rabbits at birth revealed that there is a close correlation $(r=0.914)$ between the direct measurement of PC concentration in ELF and the indirect measurement of PC concentration in ELF using the urea method (20). To further document the validity of the present method, eight young rabbits (weight 900-1100 g) were studied. These animals were intubated and ventilated. The respiratory failure and surfactant deficiency was induced by bronchoalveolar lavage, as described (24). Four rabbits received homologous surfactant intratracheally $(100 \mathrm{mg} / \mathrm{kg}$ in 4 $\mathrm{mL} / \mathrm{kg}$ saline) for the treatment of respiratory failure. Two hours after the exogenous surfactant or placebo (air), the tracheal aspirate was collected as described above. After the tracheal aspirate collection, in situ bronchoalveolar lavage was performed as follows: the animal was disconnected from the ventilator and $5 \mathrm{~mL} / \mathrm{kg}$ normal saline was introduced into the airways as a bolus. Any fluid that could be recovered was withdrawn by gentle suctioning within $10 \mathrm{~s}$. The concentrations of PC in ELF, calculated by the urea method were as follows (mean \pm SEM): lavaged animals: tracheal aspirate collection $2.1 \pm 0.3 \mathrm{mmol} / \mathrm{L}$; bronchoalveolar lavage $2.6 \pm 0.4$ $\mathrm{mmol} / \mathrm{L}(p=0.30)$; lavaged + surfactant-treated animals: tracheal aspirate collection $8.5 \pm 0.5 \mathrm{mmol} / \mathrm{L}$; bronchoalveolar lavage $7.7 \pm 0.5 \mathrm{mmol} / \mathrm{L}(p=0.15)$. Thus, the method of obtaining the specimens did not significantly influence the results.

Presentation of results. After $4 \mathrm{~d}$, because of extubation or death of the infants, aspirates were available from $<25 \%$ of the neonates in the DEX group and from $<50 \%$ of the neonates in the PL group. Therefore, the concentrations of PC, saturated PC, SP-A, albumin, and total nonsedimentable protein in ELF are shown from the specimens collected during the $4 \mathrm{~d}$ after birth. If more than one specimen from each infant was available, the mean of these is presented. For the measurement of surface activity and the inhibition of surface activity of human surfactant by nonsedimentable proteins, specimens from $\mathrm{d} 2$ to 4 were combined. Forty-nine specimens from 73 infants (DEX 40 , PL 33) were studied for the surface activity of sedimentable lipid-protein complex and 43 specimens from 65 infants (DEX 32, PL 33) for the inhibition of surface activity by proteins. In the analysis of molecular weight distribution of the nonsedimentable protein, six specimens of DEX-treated infants and six specimens of PL-treated infants were available.

Specimens of all DEX- and PL-treated neonates were compared. The first subset analysis was performed on neonates who received exogenous surfactant. In this subgroup analysis of surfactant-treated infants, only postsurfactant specimens were analyzed. The second subset analysis was performed dividing neonates into subgroups based on prenatal treatment (DEX or PL), maternal hypertension (yes or no), and surfactant therapy (yes or no). Ventilatory parameters of all infants and of surfactant-treated infants were compared. Regression analysis was used to study correlation between the severity of respiratory failure and the concentrations of surfactant components.

Multiple regression analysis was used to study the association between perinatal variables (gestational age, gender, prenatal treatment, and maternal hypertension) and neonatal outcome. Multiple regression analysis was further used to study 
the association between the surfactant indices and the following factors: gender, prenatal treatment (DEX or PL), maternal hypertension (yes or no) and exogenous surfactant therapy (yes or no). Maternal hypertension was defined as a severe pregnancy induced hypertension with or without proteinuria or as a chronic hypertension requiring antihypertensive therapy before pregnancy.

Statistics. The statistical analyses were performed using StatView software (Abacus Concepts Inc., 1987, Berkeley, CA). $t$ test, analysis of variance, $\chi^{2}$ test with continuity correction, and regression analysis were used. A $p$ value $<0.05$ was considered significant. Results are presented as means \pm SEM unless otherwise mentioned. Because of multiple comparison, the likelihood that some of the differences between the DEX and PL groups have arisen by chance is higher than indicated by the $p$ values shown.

\section{RESULTS}

Neonatal outcome and severity of respiratory failure. Seventy-six ventilator-dependent neonates born at 24-34 wk of gestation were studied. This was $71 \%$ of all neonates born at 24-34 wk of gestation and $95 \%$ of all neonates requiring ventilatory support. Clinical characteristics of the neonates are presented in Table 1. The DEX-treated neonates were more often males and tended to have a lower birth weight than the neonates in the PL group (Table 1). Prenatal DEX treatment was associated with a lower rate of RDS and a lower requirement of exogenous surfactant therapy compared with prenatal PL treatment (Table 1). However, outcome at $28 \mathrm{~d}$ of age did not differ significantly between the groups (Table 1). Low gestational age, male sex, and maternal hypertension correlated with poor neonatal outcome. In the multiple regression analysis, low gestational age $(p=0.0001)$, male sex $(p=0.021)$, and maternal hypertension $(p=0.043)$ were associated with death or severe CLD at $28 \mathrm{~d}$. Low gestational age $(p=0.0001)$ and maternal hypertension $(p=0.043)$ were associated with CLD or death at $28 \mathrm{~d}$.

Neonates treated with DEX and surfactant had a mean gestational age of $28.7 \mathrm{wk}$ and those treated with PL and surfactant 29.1 wk. In the DEX group, the first dose of surfactant was given at the postnatal age of $3.8 \mathrm{~h}$ and in the PL group at the postnatal age of $3.0 \mathrm{~h}(p=0.14)$. In each group, the

Table 1. Characteristics of the study infants, their pulmonary

\begin{tabular}{lccc}
\multicolumn{4}{c}{ morbidity, and neonatal outcome } \\
& $\begin{array}{c}\text { DEX group } \\
(n=43)\end{array}$ & $\begin{array}{c}\text { PL group } \\
(n=33)\end{array}$ & $p$ value \\
\hline Gestational age (wk) & $29.1 \pm 2.3$ & $29.1 \pm 2.6$ & 0.97 \\
Birth weight (g) & $1096 \pm 391$ & $1192 \pm 391$ & 0.29 \\
Males & $26(60 \%)$ & $11(33 \%)$ & 0.035 \\
Offspring of mother with & $19(44 \%)$ & $10(30 \%)$ & 0.32 \\
$\quad$ & & \\
$\quad$ hDypertension & $26(60 \%)$ & $28(85 \%)$ & 0.039 \\
Surfactant therapy & $21(49 \%)$ & $25(76 \%)$ & 0.032 \\
Outcome at 28 days & & & \\
$\quad$ Death & $3(7 \%)$ & $5(15 \%)$ & 0.44 \\
$\quad$ Severe CLD or death & $10(23 \%)$ & $10(30 \%)$ & 0.67 \\
$\quad$ CLD or death & $17(40 \%)$ & $13(39 \%)$ & 0.82 \\
\hline
\end{tabular}

Number of infants $(\%)$ or mean \pm SD. mean requirement of exogenous surfactant was 2.3 doses ( $p=$ 0.98 ). On the first day of life, the severity of radiographic RDS was less among the DEX-than among the PL-treated infants (DEX score 2.1, PL score $3.2 ; p=0.018$ ). Surfactant profile in the tracheal aspirate was regarded mature (high lecithin to sphingomyelin ratio and phosphatidylglycerol present) in $36 \%$ $(14 / 39)$ of the DEX-treated and in 15\% (5/33) of the PL-treated infants $(p=0.085)$. One neonate in the DEX group and two neonates in the PL group with a mature surfactant profile received exogenous surfactant.

Studying all neonates during the $24 \mathrm{~h}$ after birth, the DEXtreated neonates required less ventilatory support and supplemental oxygen than the PL-treated neonates (Fig. 1). Thereafter, no significant difference between the DEX and PL groups was noticed. Before the first dose of surfactant, the requirement of supplemental oxygen or ventilatory support did not differ significantly between the DEX and PL groups (Fig. 2). During $24 \mathrm{~h}$ after the first dose of surfactant, the neonates in the DEX group required lower ventilatory pressures and less supplemental oxygen than the neonates in the PL group (Fig. 2).

Concentrations of $P C$, saturated PC, and $S P-A$ in $E L F$; and ratios between $S P-A, P C$, and saturated $P C$. The concentrations of surfactant components in ELF did not differ between the DEX and PL groups, whether all infants or only surfactanttreated infants were studied (Table 2). The concentrations of saturated PC in ELF did not differ between the DEX and PL groups, either (data not shown). In the specimens collected on the first day of life, concentrations of SP-A in ELF were studied in the subgroups. Infants were divided into subgroups based on maternal hypertension, prenatal treatment, and sur-
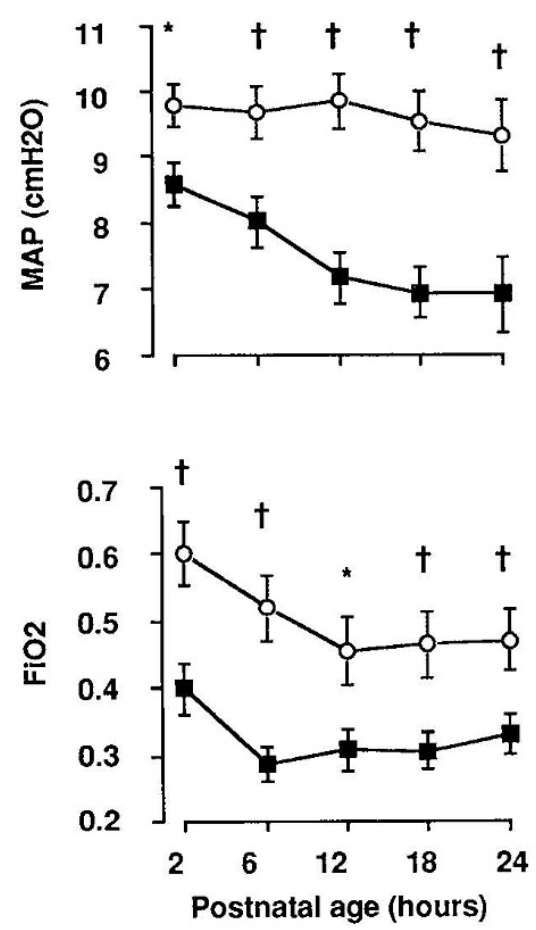

Figure 1. Ventilatory parameters of all infants during $24 \mathrm{~h}$ after birth. Mean airway pressure (MAP; $\mathrm{cm} \mathrm{H} \mathrm{H}_{2} \mathrm{O}$ ) and fractional inspiratory oxygen $\left(\mathrm{FiO}_{2}\right)$. Conversion: $10 \mathrm{~cm} \mathrm{H}_{2} \mathrm{O}=1 \mathrm{kPa} .{ }^{*} p<0.05, \dagger p<0.01$ for comparisons between the DEX $(\mathbf{\square}$ and PL $(O)$ group. 

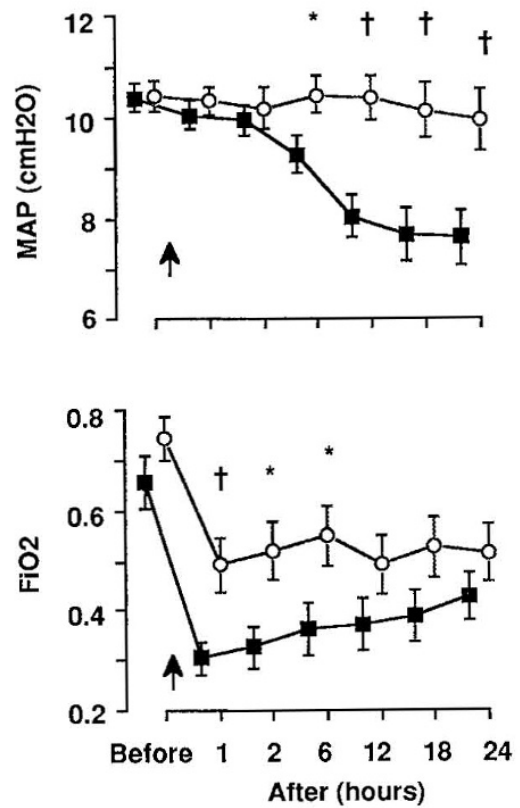

Figure 2. Ventilatory parameters of surfactant-treated infants before and during the $24 \mathrm{~h}$ after administration of the first dose of exogenous surfactant. Abbreviations are the same as those in Figure 1. Bars have been slightly shifted to prevent overlapping. Arrow indicates surfactant administration. Conversion: $10 \mathrm{~cm} \mathrm{H}_{2} \mathrm{O}=1 \mathrm{kPa} .{ }^{*} p<0.05, \dagger p<0.01$ for comparisons between the DEX $(\square)$ and PL $(O)$ group.

Table 2. Concentrations of $P C$ and SP-A in ELF

\begin{tabular}{ccccc}
\hline & \multicolumn{2}{c}{ All infants } & \multicolumn{2}{c}{ Surfactant-treated infants } \\
\cline { 2 - 5 } & DEX group & PL group & DEX group & PL group \\
\hline $\begin{array}{c}\text { PC }]_{\text {ELF }}(\mathrm{mmol} / \mathrm{L}) \\
\text { at age }(\mathrm{h})\end{array}$ & & & & \\
$0-24$ & $27.5 \pm 5.3$ & $23.5 \pm 5.0$ & $17.5 \pm 3.5$ & $26.9 \pm 7.4$ \\
& $(n=40)$ & $(n=30)$ & $(n=18)$ & $(n=19)$ \\
& $12.0 \pm 1.7$ & $14.7 \pm 2.5$ & $12.1 \pm 2.2$ & $16.9 \pm 3.1$ \\
$25-48$ & $(n=28)$ & $(n=27)$ & $(n=16)$ & $(n=21)$ \\
& $15.7 \pm 2.9$ & $11.7 \pm 1.6$ & $15.4 \pm 2.9$ & $11.0 \pm 1.9$ \\
$49-96$ & $(n=24)$ & $(n=25)$ & $(n=18)$ & $(n=20)$ \\
& & & & \\
{$[\mathrm{SP}-\mathrm{A}]_{\text {ELF }}(\mathrm{g} / \mathrm{L})$ at } & & & & \\
age $(\mathrm{h})$ & $0.21 \pm 0.05$ & $0.16 \pm 0.04$ & $0.26 \pm 0.09$ & $0.20 \pm 0.06$ \\
$0-24$ & $(n=40)$ & $(n=28)$ & $(n=18)$ & $(n=21)$ \\
& $0.15 \pm 0.03$ & $0.18 \pm 0.03$ & $0.17 \pm 0.05$ & $0.20 \pm 0.04$ \\
$25-48$ & $(n=28)$ & $(n=25)$ & $(n=16)$ & $(n=19)$ \\
& $0.35 \pm 0.06$ & $0.30 \pm 0.05$ & $0.39 \pm 0.07$ & $0.31 \pm 0.07$ \\
$49-96$ & $(n=24)$ & $(n=25)$ & $(n=18)$ & $(n=20)$ \\
& & & &
\end{tabular}

All comparisons NS.

factant therapy. Concentrations of SP-A in ELF were as follows: DEX $0.21 \mathrm{~g} / \mathrm{L}$; DEX + hypertension $0.08 \mathrm{~g} / \mathrm{L}$; DEX + surfactant $0.38 \mathrm{~g} / \mathrm{L} ; \mathrm{DEX}+$ hypertension + surfactant 0.15 $\mathrm{g} / \mathrm{L} ;$ PL $0.14 \mathrm{~g} / \mathrm{L} ; \mathrm{PL}+$ hypertension $0.05 \mathrm{~g} / \mathrm{L} ; \mathrm{PL}+$ surfactant $0.25 \mathrm{~g} / \mathrm{L} ; \mathrm{PL}+$ hypertension + surfactant $0.07 \mathrm{~g} / \mathrm{L}$ (all comparisons NS).

The ratios of SP-A to PC in AS are presented in Table 3. Among all DEX- and PL-treated infants, the ratios of SP-A to PC did not differ between the groups. In the specimens collected during the $24 \mathrm{~h}$ after birth, the infants in the DEX + surfactant group tended to have higher SP-A to PC ratios than the infants in the $\mathrm{PL}+$ surfactant group $(p=0.09)$. SP-A to $\mathrm{PC}$ ratios were similarly studied in the subgroups as were
Table 3. Ratios of SP-A to PC in AS

\begin{tabular}{cccccc}
\hline \multirow{2}{*}{$\begin{array}{c}\text { SP-A/PC }(\mathrm{g} / \mathrm{mol}) \\
\text { at age }(\mathrm{h}):\end{array}$} & \multicolumn{2}{c}{ All infants } & \multicolumn{2}{c}{ Surfactant-treated infants } \\
\cline { 2 - 3 } \cline { 5 - 6 } \cline { 5 - 6 } & DEX group & PL group & & DEX group & PL group \\
\hline $0-24$ & $9.8 \pm 1.5$ & $8.1 \pm 1.3$ & & $14.5 \pm 2.3$ & $9.5 \pm 1.8$ \\
& $(n=40)$ & $(n=28)$ & $(n=18)$ & $(n=18)$ \\
$25-48$ & $11.9 \pm 1.7$ & $18.3 \pm 3.1$ & $14.1 \pm 2.8$ & $17.1 \pm 1.8$ \\
& $(n=28)$ & $(n=27)$ & $(n=16)$ & $(n=21)$ \\
$49-92$ & $26.6 \pm 5.1$ & $24.7 \pm 3.6$ & $32.0 \pm 6.3$ & $26.2 \pm 4.5$ \\
& $(n=24)$ & $(n=24)$ & $(n=18)$ & $(n=19)$ \\
\hline
\end{tabular}

All comparisons NS.

concentrations of SP-A in ELF. SP-A to PC ratios were as follows: DEX $8.9 \mathrm{~g} / \mathrm{mol}$; DEX + hypertension $1.8 \mathrm{~g} / \mathrm{mol}$; DEX + surfactant $17.4 \mathrm{~g} / \mathrm{mol}$; DEX + hypertension + surfactant $11.7 \mathrm{~g} / \mathrm{mol}$; PL $5.3 \mathrm{~g} / \mathrm{mol}$; PL + hypertension $7.1 \mathrm{~g} / \mathrm{mol} ; \mathrm{PL}+$ surfactant $9.7 \mathrm{~g} / \mathrm{mol} ; \mathrm{PL}+$ hypertension + surfactant 8.9 $\mathrm{g} / \mathrm{mol}(p=0.010)$. In the subgroup comparisons, SP-A to PC ratios were significantly higher in the DEX group than in the DEX + hypertension group $(p<0.05)$, and in the DEX + surfactant than in the PL + surfactant group $(p<0.05)$.

The ratios of saturated $\mathrm{PC}$ to $\mathrm{PC}$ were similar in both groups (saturated PC/PC mmol $\times \mathrm{L}^{-1} / \mathrm{mmol} \times \mathrm{L}^{-1} \mathrm{~d} 1$ : DEX 0.75, PL 0.71; d 2: DEX 0.68, PL 0.71; d 3-4: DEX 0.65, PL 0.63, all comparisons NS).

Factors associated with surfactant indices. Multiple regression analysis was used to study the impact of gender, prenatal treament (DEX or PL), maternal hypertension (yes or no), and exogenous surfactant therapy (yes or no) on the following surfactant indices: $[\mathrm{SP}-\mathrm{A}]_{\mathrm{ELF}},[\mathrm{PC}]_{\mathrm{ELF}}$, [saturated PC $]_{\mathrm{ELF}}$, and the ratios of SP-A/PC and SP-A/saturated PC (Table 4). No significant correlation was seen between the gender and the surfactant indices. On the first day of life, neither prenatal treatment, maternal hypertension, nor surfactant therapy correlated with saturated PC or PC levels in ELF (data not shown). Maternal hypertension was associated with low SP-A levels and low SP-A to PC ratios on the first day of life. Both prenatal DEX and exogenous surfactant therapy were associated with high SP-A to PC ratios during the first day of life (Table 4). Similarly, maternal hypertension was associated with low SP-A to saturated PC ratios, and prenatal DEX and exogenous surfactant therapy with high SP-A to saturated PC ratios (data not shown).

Table 4. Factors correlating with concentrations of SP-A and ratios of SP-A to PC on the first day of life: multiple regression analysis

\begin{tabular}{lrrl}
\hline \multicolumn{1}{c}{ Variable } & $\begin{array}{c}\text { Regression } \\
\text { coefficient }\end{array}$ & SEM & $p$ value \\
\hline [SP-A $]_{\text {ELF }}$ & & & \\
Maternal hypertension* & -0.18 & 0.06 & 0.007 \\
Prenatal dexamethasone* & 0.10 & 0.07 & 0.12 \\
Exogenous surfactant therapy* & 0.11 & 0.06 & 0.094 \\
$n=68, r=0.378$ & & & \\
SP-A/PC & & & \\
Maternal hypertension* & -4.4 & 1.9 & 0.025 \\
Prenatal dexamethasone* & 4.4 & 2.0 & 0.030 \\
Exogenous surfactant therapy* & 6.9 & 2.0 & 0.001 \\
$n=68, r=0.465$ & & & \\
\hline
\end{tabular}

* No $=0$, yes $=1$. 
Concentration of total nonsedimentable protein in ELF. The concentration of the total nonsedimentable protein in ELF is presented in Figure 3. On the first and second day of life, the DEX-treated infants had a lower concentration of protein in ELF than the PL-treated infants regardless whether all infants or only the surfactant-treated infants were studied. Thereafter, the protein concentrations did not differ between the groups. In specimens recovered during the first day of life, the molecular weight distribution did not differ between the DEX and PL groups (data not shown).

The ratio of albumin in ELF to albumin in serum was lower in the DEX- than in the PL-treated infants in specimens collected on the first day of life. This was evident if all infants ([albumin $]_{\text {ELF }} /[\text { albumin }]_{\text {scrum }} \mathrm{g} \times \mathrm{L}^{-1} / \mathrm{g} \times \mathrm{L}^{-1}$ : DEX $0.22 \pm$ 0.02 ; PL $0.43 \pm 0.11 ; p=0.046$ ) or if only the surfactanttreated infants (DEX $0.18 \pm 0.03$; PL $0.54 \pm 0.17 ; p=0.041$ ) were studied. The ratio of albumin to total nonsedimentable protein in AS was similar in the DEX and PL groups (data not shown).

Surface activity of endogenous surfactant complex and effect of nonsedimentable protein on surface activity of human surfactant in vitro. The surface activity of the endogenous surfactant complex isolated from AS was studied (Table $5)$. In the present in vitro conditions, less than $10 \%$ of all specimens were surface active (i.e. minimum surface tension $<10 \mathrm{mN} / \mathrm{m}$ ). In contrast, the surfactant used for the treatment of RDS was always surface active. On the first day of life, the DEX-treated infants had a significantly lower minimum surface tension of the sedimentable lipid-protein complex than the PL-treated infants. The endogenous surfactant complex, from the infants treated with DEX and surfactant, had a significantly lower minimum surface tension than the surfactant complex
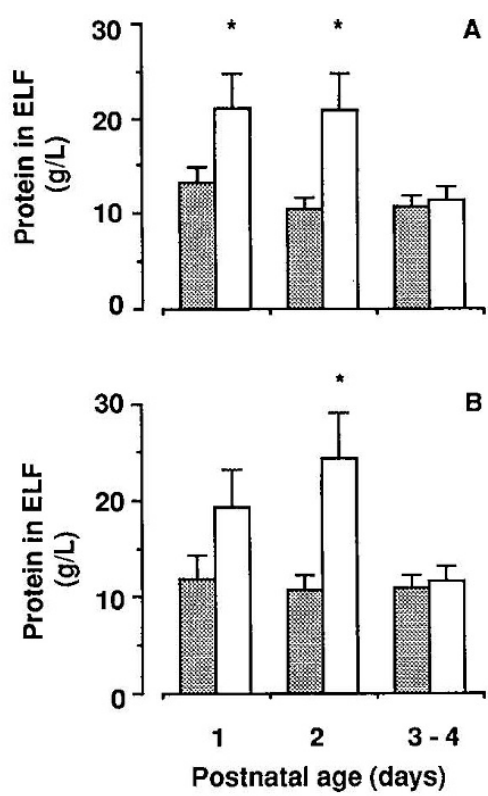

Figure 3. Concentrations of total nonsedimentable protein $(g / L)$ during $4 d$ after birth in ELF of all infants $(A)$ and surfactant-treated infants $(B)$. Number of specimen: $A$, all infants: 1 d DEX 40, PL 28; 2 d DEX 28, PL 27; 3-4 d DEX 23, PL 24; and $B$, surfactant-treated infants: $1 \mathrm{~d}$ DEX 18, PL $18 ; 2 \mathrm{~d} \mathrm{DEX}$ 16, PL 21; 3-4 d DEX 17, PL 19. * $p<0.05$ for comparisons between the DEX (䛛) and PL ( $\square$ ) group. from the infants treated with PL and surfactant. In the equilibrium surface tension or in the surface adsorption, no detectable difference was seen between the DEX and PL groups (data not shown).

The inhibitory effect of the nonsedimentable protein, at a constant concentration of $4 \mathrm{~g} / \mathrm{L}$, on the surface activity of human surfactant was further studied (Fig. 4, Table 6). On the first day of life, the minimum surface tension of human surfactant in the presence of the nonsedimentable protein was significantly lower in the DEX-than in the PL-treated infants (Fig. 4). The nonsedimentable protein from the PL-treated infants inhibited the surface adsorption more than the protein from the DEX-treated infants (Table 6). After the first day of life, no difference was noted between the two groups for any of these parameters.

Correlation between $P C$ in ELF and respiratory failure. The association between the surfactant indices and the severity of respiratory failure, expressed as MAP $\times \mathrm{FiO}_{2}\left(\mathrm{~cm} \mathrm{H}_{2} \mathrm{O}\right)$, was further studied. The hypothesis tested was whether during early life there are differences in the association between the surfactant indices and the severity of respiratory failure when infants treated with DEX or PL are compared. On the first day of life, among the DEX-treated infants, the concentration of PC was associated with the degree of respiratory failure as follows: $\mathrm{MAP} \times \mathrm{FiO}_{2}=-0.19 \times \log [\mathrm{PC}]_{\mathrm{ELF}}+4.57 ; r=-0.708, p$ $=0.0002$. Among the PL-treated infants this association was not significant: $\mathrm{MAP} \times \mathrm{Fio}_{2}=-0.003 \log [\mathrm{PC}]_{\mathrm{ELF}}+4.10$; $r=-0.020 ; p=0.94$.

\section{DISCUSSION}

Surfactant deficiency demonstrated as low lecithin to sphingomyelin ratio and low concentration of surfactant characterize the early course of RDS. In the present study several hours after birth, the infants treated with exogenous surfactant and those with mild or no RDS had high concentrations of surfactant phospholipids in ELF. Prenatal DEX treatment had no significant effect on these concentrations. Despite this, the DEX-treated infants had less severe respiratory failure, fewer infants required surfactant for the treatment of RDS, and those treated with surfactant had a more striking decrease in the severity of respiratory failure during the the first day of life than the PL-treated infants. According to one interpretation of the present results, the beneficial effects of prenatal DEX on the incidence and severity of respiratory failure may seem to be unrelated to the surfactant system.

In studies using lung explants, glucocorticoids increase the synthesis of surfactant phospholipids (7). However, results of most in vivo studies differ from those of in vitro. Prenatal glucocorticoid treatment has increased the concentrations of total and saturated surfactant phospholipids in some unventilated fetal animals $(10,25)$, but not in all $(8,9)$. After mechanical ventilation, prenatal glucocorticoid treatment has had no consistent effect on the size of the total or saturated alveolar phospholipid pool in preterm rabbits or sheep $(10,12,13)$. Our results indicate that prenatal steroid treatment influences the surfactant system at birth by means other than increasing the 
Table 5. Minimum surface tension of surfactant complex isolated from AS

\begin{tabular}{|c|c|c|c|c|}
\hline \multirow{2}{*}{$\begin{array}{l}\text { Minimum surface tension of surfactant } \\
\text { complex }(\mathrm{mN} / \mathrm{m}) \text { at postnatal age }(\mathrm{h}) \text { : }\end{array}$} & \multicolumn{2}{|c|}{ All infants } & \multicolumn{2}{|c|}{ Surfactant-treated infants } \\
\hline & DEX group & PL group & DEX group & PL group \\
\hline $0-24$ & $\begin{array}{l}12.7 \pm 0.9 \\
(n=12)\end{array}$ & $\begin{array}{l}15.2 \pm 0.5^{*} \\
(n=15)\end{array}$ & $\begin{array}{l}13.4 \pm 0.5 \\
(n=8)\end{array}$ & $\begin{array}{l}16.1 \pm 0.4 \dagger \\
(n=11)\end{array}$ \\
\hline $25-96$ & $\begin{array}{l}13.0 \pm 0.6 \\
(n=10)\end{array}$ & $\begin{array}{r}13.9 \pm 0.6 \\
(n=12)\end{array}$ & $\begin{array}{c}13.7 \pm 0.2 \\
(n=7)\end{array}$ & $\begin{array}{r}14.5 \pm 0.6 \\
(n=10)\end{array}$ \\
\hline
\end{tabular}

The minimum surface tension was recorded after 5 -min pulsation of the bubble. The phosphatidylcholine concentration was adjusted to $2 \mu \mathrm{mol} / \mathrm{mL}$. For the measurement of surface tension of the sedimentable lipid-protein complex specimens of 1 to 5 infants were combined.

${ }^{*} p=0.014$ compared to DEX group.

$\dagger p<0.02$ compared to DEX + surfactant group.
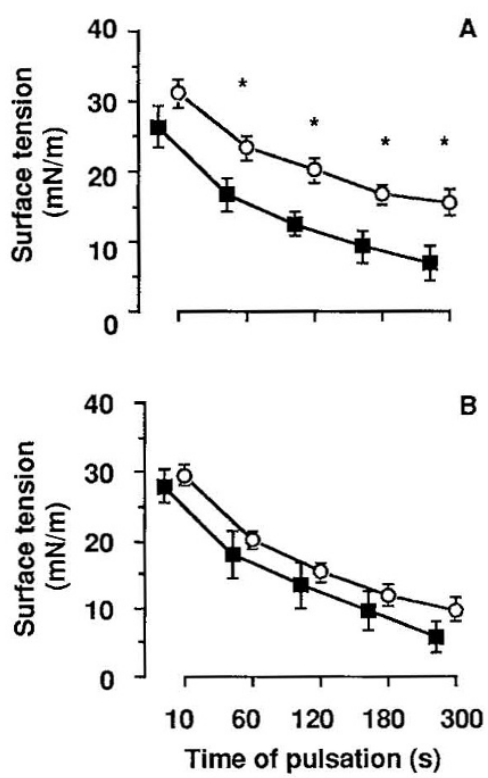

Figure 4. Inhibitory effect of total nonsedimentable protein isolated from airway specimens on minimum surface tension $(\mathrm{mN} / \mathrm{m})$ of human surfactant on the first $(A)$ and second to fourth $(B)$ day of life. Bars have been slightly shifted to prevent overlapping. Concentration of protein in nonsedimentable fraction was adjusted to $4 \mathrm{~g} / \mathrm{L}$, final concentration of surfactant PC was $1.8 \mathrm{mmol} / \mathrm{L}$. The minimum surface tension of human surfactant without inhibitor, $0 \mathrm{mN} / \mathrm{m}$, was reached within $120 \mathrm{~s}$ after formation of the bubble. Number of specimens: $A$, DEX 6, PL 12; $B$, DEX 7, PL 18. * $p<0.05$ for comparisons between the $\mathrm{DEX}(\square)$ and PL (O) group.

pool size or the concentration of surfactant phospholipids in ELF.

Glucocorticoids may affect the alveolar pool size of surfactant proteins. In studies using human fetal lung explant, glucocorticoids have both a stimulatory and an inhibitory effect on the SP-A synthesis: low doses and short exposure stimulate, whereas high doses and long exposure inhibit the synthesis of SP-A (7). Furthermore, prenatal glucocorticoid treatment increases the expression of SP-A in the whole lung of the rat fetus (26), and prenatal glucocorticoid treatment combined with TSH-releasing hormone or fetal interventions increases the alveolar pool size of SP-A in ventilated preterm sheep (12, 27). In the present study, prenatal glucocorticoid administration tended to increase the ratio between SP-A and PC on the first day of life. The increase in SP-A to PC ratio after prenatal DEX treatment was significant in infants who had received SP-A-containing exogenous surfactant within $24 \mathrm{~h}$ and who were offspring of mothers without hypertension. On the basis of the high SP-A relative to PC after surfactant administration in DEX-treated infants, we propose that prenatal DEX treatment delays the clearance of SP-A from ELF.

Offspring of mothers with hypertension had low SP-A concentrations in ELF and low SP-A to PC ratios, despite prenatal DEX and surfactant treatment; these infants had also a poor neonatal outcome. Previously, it has been demonstrated that the ratio of SP-A to saturated PC in the amniotic fluid in the severe preeclampsia is higher than in the normal pregnancy (28). Present results may indicate that the preterm offspring of mothers with hypertension have abnormally high catabolism or clearance of SP-A. In addition, our results are consistent with the previous findings that low SP-A levels in preterm or term neonates are associated with severe respiratory failure (29) and later with death or $\operatorname{CLD}(20,30)$.

Based on in vitro studies, surfactant proteins have been shown to have several functions. SP-A down-regulates surfactant phospholipid secretion (31) and stimulates phospholipid uptake by type II pneumocytes (32). It has immunomodulatory properties that improve the macrophage defense against microorganisms (33). Further, this protein protects the surfactant complex against inhibitors of surface activity $(34,35)$ and inhibits conversion of surfactant subtypes from large aggregate forms to small aggregate forms (36). Surfactant proteins B and $\mathrm{C}$, present in natural surfactants, enhance the surface activity of surfactant phospholipids (37).

In the alveoli, surfactant complex exists in several subtypes differing in their density characteristics and in their ability to decrease surface tension (38). Light subtypes are phospholipidrich, protein-poor small vesicles that are not surface active. Heavy and ultraheavy subtypes are large aggregates that contain surfactant proteins and are surface active. In the present study, the surfactant complex, isolated from AS by differential centrifugation, contained large aggregates. Both in the DEXand PL-treated infants, more than $90 \%$ of immunoreactive SP-A was recovered in the surfactant fraction. The surfactant complex, isolated from specimens of PL-treated infants, was less surface active than the surfactant complex from DEXtreated infants. Prenatal DEX may alter the composition or intra-alveolar metabolism of the surfactant complex. However, the cause of the difference in the surface activity of surfactant complex remains unknown. The human surfactant used for the treatment of RDS was more surface active than the surfactant complex isolated from AS of preterm neonates. Our results are different from those of Ikegami et al. (39) who, using an in vivo preterm animal model, demonstrated that the function of ex- 
Table 6. Effect of total nonsedimentable protein isolated from AS on surface adsorption and equilibrium surface tension of human surfactant

\begin{tabular}{lcccc}
\hline & \multicolumn{2}{c}{ Postnatal age 0-1 d } & & \multicolumn{2}{c}{ Postnatal age 2-4 d } \\
\cline { 5 - 6 } & $\begin{array}{c}\text { DEX group } \\
(n=6)\end{array}$ & $\begin{array}{c}\text { PL group } \\
(n=12)\end{array}$ & $\begin{array}{c}\text { DEX group } \\
(n=7)\end{array}$ & $\begin{array}{c}\text { PL group } \\
(n=18)\end{array}$ \\
\hline Surface adsorption: surface tension $(\mathrm{mN} / \mathrm{m}) 1 \mathrm{~s}$ after formation of the bubble & $30.8 \pm 1.2$ & $38.4 \pm 1.7^{*}$ & $30.6 \pm 1.5$ & $35.9 \pm 1.6$ \\
Equilibrium surface tension $(\mathrm{mN} / \mathrm{m})$ & $25.4 \pm 0.4$ & $30.5 \pm 1.6$ & $25.4 \pm 0.8$ & $28.3 \pm 1.1$ \\
\hline
\end{tabular}

Concentration of protein in non-sedimentable fraction was adjusted to $4 \mathrm{~g} / \mathrm{L}$, and final concentration of surfactant phosphatidylcholine was $1.8 \mathrm{mmol} / \mathrm{L}$. The minimum surface tension of human surfactant without inhibitor, $0 \mathrm{mN} / \mathrm{m}$, was reached within $120 \mathrm{~s}$ after formation of the bubble. In all except one instance, protein in specimens from 2 to 8 infants was combined.

${ }^{*} p<0.05$, other comparisons NS.

ogenous surfactant is improved in the preterm lung. Differences in the recipient characteristics and in the exogenous surfactants between our study and the study of Ikegami et al. (39) could explain the apparently contradictory results.

DEX-treated infants had a lower concentration of nonsedimentable protein in ELF and a lower ratio of albumin in ELF to albumin in serum than did PL-treated infants. This suggests that prenatal DEX treatment decreases alveolar-capillary permeability. High alveolar capillary permeability shortly after birth is characteristic of acute lung injury seen both in preterm animals and preterm infants with RDS (40-42). In ventilated animals, both prenatal steroid treatment $(11,12)$ and exogenous surfactant therapy have been shown to decrease the concentrations of protein in bronchoalveolar fluid $(11,43,44)$. In rabbits, the combination therapy of prenatal steroid and exogenous surfactant decreases protein leak into alveoli or improves alveolar clearance of protein more than either treatment alone (11). Our results are consistent with the reports from animal studies and suggest that prenatal DEX improves integrity of capillary endothelium and/or increases the clearance of the plasma-derived proteins from alveolar space.

Plasma-derived proteins have been shown to increase minimum surface tension of surfactant complex and this increase is dependent on the concentration of the inhibitor (40). According to the present results, prenatal DEX treatment decreased the inhibition of surfactant function by proteins in ELF. The low concentration of nonsedimentable protein in ELF after prenatal DEX treatment is likely to be associated with improved surfactant function. In addition, the nonsedimentable fraction from DEX-treated infants decreased the surface activity of human surfactant less than the same concentration of protein from PL-treated infants. In the analysis of the molecular weight distribution of the nonsedimentable fraction, no detectable differences were seen between the DEX and PL-treated infants. Thus, the cause of difference in the activity of surfactant inhibitors remains unknown.

As a result of increased surface activity, ventilatory pressures are better transmitted beyond the air-liquid interface. In the DEX-treated infants, the improvement in gas exchange, the reduction in lung edema, and the lower ventilatory requirements after surfactant treatment may in part be due to improved surfactant function. Concentrations of PC in ELF correlated inversely with the degree of respiratory failure in the DEXtreated infants but not in the PL-treated infants. Despite adequate surfactant concentration, many PL-treated and some DEX-treated infants had moderate to severe respiratory failure.
This suggests that functionally poor surfactant as well as other factors such as poor distribution of surfactant, high permeability lung edema, or deficient clearance of the lung fluid may contribute to the severity of the respiratory failure. As judged on the basis of the chest radiographs, prenatal DEX treatment was associated with improved aeration and less severe lung edema than prenatal PL. The decrease in the concentration requirements of surfactant in ELF and the less severe pulmonary edema in chest radiographs after prenatal DEX than PL treatment may additionally indicate that prenatal DEX promotes structural maturation of the lungs in preterm infants, as has been shown in preterm animals $(8,9)$.

Several factors improved the surfactant function after prenatal DEX. These include decreased concentration of protein in ELF, decreased activity of this protein to increase surface tension, increased secretion rate of surfactant at birth (associated with lower incidence of RDS), and improved intraalveolar metabolism of exogenous surfactant in RDS. However, these effects of glucocorticoid on the surfactant system and lung function remained detectable only for 1-2 d after birth. It is unclear why the period of postnatal improvement of surfactant function was apparently short-lasting and why the offspring of mothers with severe hypertension had no benefit from the therapy. There is a need to evaluate whether any new therapy or timing of therapy will further improve the neonatal transition and decrease the incidence of CLD among the high risk infants.

Acknowledgment. The authors thank Organon Company for providing the dexamethasone and placebo ampules.

\section{REFERENCES}

1. Crowley P, Chalmers I, Keirse MJNC 1990 The effects of corticosteroid administration before preterm delivery: an overview of the evidence from controlled trials. $\mathrm{Br}$ J Obstet Gynaecol 97:11-25

2. Jobe AH 1993 Pulmonary surfactant therapy. N Engl J Med 328:861-868

3. Cotton RB, Olsson $T$, Law AB, Parker RA, Lindström DP, Silberberg AR, Sundell HW, Sandberg K 1993 The physiologic effects of surfactant treatment on gas exchange in newborn premature infants with hyaline membrane disease. Pediatr Res 34:495-501

4. Jobe AH, Mitchell BR, Gunkel JH 1993 Beneficial effects of the combined use of prenatal corticosteroids and postnatal surfactant on preterm infants. Am J Obstet Gynecol 168:508-513

5. Liggins GC 1969 Premature delivery of fetal lambs infused with glucocorticoids $\mathrm{J}$ Endocrinol 45:515-523

6. deLemos RA, Shermeta DW, Knelson JH, Kotas R, Avery ME 1970 Acceleration of appearance of pulmonary surfactant in the fetal lamb by administration of corticosteroids. Am Rev Respir Dis 102:459-461

7. Ballard PL 1989 Hormonal regulation of pulmonary surfactant 1989. Endocr Rey 10:165-181 
8. Beck JC, Mitzner W, Johnson JWC, Hutchins GM, Foidart J-M, London WT, Palmer AE, Scott R 1981 Betamethasone and the rhesus fetus: effect on lung morphometry and connective tissue. Pediatr Res 15:235-240

9. Schellenberg J-C, Liggins GC, Stewart AW 1987 Growth, elastin concentration, and collagen concentration of perinatal lung: effects of dexamethasone. Pediatr Res 21:603-607

10. Fiascone JM, Jacobs HC, Moya FR, Mercurio MR, Lima DM 1987 Betamethasone increases pulmonary compliance in part by surfactant- independent mechanisms in preterm rabbits. Pediatr Res 22:730-735

11. Ikegami M, Berry D, ElKady T, Pettenazzo A, Seidner S, Jobe A 1987 Corticosteroids and surfactant change lung function and protein leaks in the lungs of ventilated premature rabbits. J Clin Invest 79:1371-1378

12. Ikegami M, Polk D, Tabor B, Lewis J, Yamada T, Jobe A 1991 Corticosteroid and thyrotropin-releasing hormone effects on preterm sheep lung function. J Appl Physiol 70:2268-2278

13. Seidner S, Rider E, Jobe A, Yamada T, Ikegami M 1992 Effects of antenatal thyrotropin-releasing hormone, antenatal corticosteroids, and postnatal ventilation on surfactant mobilization in premature rabbits. Am J Obstet Gynecol 166:1551-1559

14. Kari MA, Hallman M, Eronen M, Teramo K, Virtanen M, Koivisto M, Ikonen RS 1994 Prenatal dexamethasone treatment in conjunction with rescue therapy of human surfactant-- a randomized placebo-controlled multicenter study. Pediatrics 93:730736

15. Hallman M, Merritt TA, Schneider H, Epstein BL, Mannino F, Edwards DK, Gluck L 1983 Isolation of human surfactant from amniotic fluid and a pilot study of its efficacy in respiratory distress syndrome. Pediatrics 71:473-482

16. Merritt TA, Hallman M, Berry C, Pohjavuori M, Edwards III DK, Jääskeläinen J, Grafe MR, Vaucher Y, Wozniack P, Heldt G, Rapola J 1991 Randomized, placebocontrolled trial of human surfactant given at birth versus rescue administration in very low birth weight infants with lung immaturity. J Pediatr 118:581-594

17. Edwards DK, Hilton SvW, Merritt TA, Hallman M, Mannino F, Boynton BR 1985 Respiratory distress syndrome treated with human surfactant: radiographic findings. Radiology 157:329-334

18. Kuroki Y, Takahashi H, Fukada Y, Mikawa M, Inagawa A, Fujimoto S, Akino T 1985 Two-site "simultaneous" immuoassay with monoclonal antibodies for the determination of surfactant apoporteins in human amniotic fluid. Pediatr Res 19:1017-1020

19. Peterson GL 1977 A simplification of the protein assay method of Lowry et al, which is more generally applicable. Anal Biochem 83:346-356

20. Hallman M, Merritt TA, Akino T, Bry K 1991 Surfactant protein A, phosphatidylcholine, and surfactant inhibitors in epithelial lining fluid: correlation with surface activity, severity of respiratory distress syndrome, and outcome in small premature infants. Am Rev Respir Dis 144:1376-1384

21. Hallman M, Teramo K 1981 Measurement of the lecithin/sphingomyelin ratio and phosphatidylglycerol in amniotic fluid: an accurate method for the assessment of fetal lung maturity. Br J Obstet Gynaecol 88:806-813

22. Enhörning G 1977 Pulsating bubble technique for evaluating pulmonary surfactant. J Appl Physiol 43:198-203

23. Rennerd SI, Basset G, Lecossier D, O'Donnell KM, Pinkston P, Martin PG, Crystal RG 1986 Estimation of volume of epithelial lining fluid recovered by lavage using urea as a marker of dilution. J Appl Physiol 60:532-538

24. Hallman M, Sarnesto A, Bry K 1994 Interaction of transferrin saturated with iron with lung surfactant in respiratory failure. $\mathrm{J}$ Appl Physiol 77:757-766

25. Warburton D, Parton L, Buckley S, Cosico L, Enns G, Saluna T 1988 Combined effects of corticosteroid, thyroid hormones, and $\beta$-agonists on surfactant, pulmonary mechanics, and $\beta$-receptor binding in fetal lamb lung. Pediatr Res 24:166-170
26. Shellhase DE, Shannon JM 1991 Effects of maternal dexamethasone on expression of SP-A, SP-B, SP-C in the fetal rat lung. Am J Respir Cell Mol Biol 4:304-312

27. Tabor BL, Lewis JF, Ikegami M, Polk D, Jobe AH 1994 Corticosteroids and fetal intervention interact to alter lung maturation in preterm lambs. Pediatr Res 35:479483

28. Hallman M, Arjomaa P, Hoppu K, Teramo K, Akino T 1989 Surfactant protein in the diagnosis of fetal lung maturity II: the $35 \mathrm{kD}$ protein and phospholipids in complicated pregnancy. Am J Obstet Gynecol 161:965-969

29. Moya FR, Montes HF, Thomas VL, Mouzinho AM, Smith JF, Rosenfeld CR 1994 Surfactant protein A, saturated phosphatidylcholine in respiratory distress syndrome. Am J Respir Crit Care Med 150:1672-1677

30. Bui KC, Walther FJ, David-Cu R, Garg M, Warburton D 1992 Phospholipid and surfactant protein-A concentrations in tracheal aspirates from infants requiring extracorporeal membrane oxygenation. J Pediatr 121:271-274

31. Rice WR, Ross GF, Singleton FM, Dingle S, Whitsett JA 1987 Surfactant associated protein inhibits phospholipid secretion from type II cells. J Appl Physiol 63:692-698

32. Wright JR, Wager RE, Hawgood S, Dobbs L, Clemets JA 1987 Surfactant apoprotein $M_{r}=26,000-36,000$ enhances uptake of liposomes by type II cells. J Biol Chem 262:2888-2894

33. Van Iwaarden F, Welmers B, Verhoef J, Haagsman HP, Van Golde LMG 1990 Pulmonary surfactant protein $A$ enhances the host-defense mechanism of rat alveolar macrophages. Am J Respir Cell Mol Biol 2:91-98

34. Cockshutt AM, Weitz J, Possmayer F 1990 Pulmonary surfactant associated protein A enhances the surface activity of lipid extract surfactant and reverses inhibition by blood proteins in vitro. Biochemistry 29:8424-8429

35. Hallman M, Merritt TA, Strayer D, Arjomaa P 1990 Is it possible to enhance the therapeutic effect of exogenous natural surfactant. Progr Respir Res 25:256-264

36. Higuchi R, Lewis J, Ikegami M 1992 In vitro conversion of surfactant subtypes is altered in alveolar surfactant isolated from injured lungs. Am Rev Respir Dis 145:1416-1420

37. Whitsett JA, Baatz JE 1992 Hydrophobic surfactant proteins SP-B, SP-C: molecular biology, structure, and function. In: Robertson B, Van Golde LMG, Batenburg JJ (eds) Pulmonary Surfactant from Molecular Biology to Clinical Practice. Elsevier, Amsterdam, pp 55-75

38. Baritussio A, Alberti A, Quaglino D, Pettenazzo A, Dalzoppo D, Sartori L, PasqualiRonchetti I 1994 SP-A, SP-B, SP-C in surfactant subtypes around birth: reexamination of alveolar life cycle of surfactant. Am J Physiol 266:L436-L447

39. Ikegami M, Ueda T, Absolom D, Baxter C, Rider E, Jobe AH 1993 Changes in exogenous surfactant in ventilated preterm lamb lungs. Am Rev Respir Dis 148:837844

40. Ikegami M, Jobe A, Jacobs H, Lam R 1984 A protein from airways of premature lambs that inhibits surfactant function. J Appl Physiol 57:1134- 1142

41. Bland RD, Carlton DP, Scheerer RG, Cummings JJ, Chapman DL 1989 Lung fluid balance in lambs before and after premature birth. J Clin Invest 84:568- 576

42. Jefferies AL, Coates G, O'Brodovich H 1984 Pulmonary epithelial permeability in hyaline-membrane disease. N Engl J Med 311:1075-1080

43. Ikegami M, Jobe AH, Tabor BL. Rider EL, Lewis JF 1992 Lung albumin recovery in surfactant-treated preterm ventilated lambs. Am Rev Respir Dis 145:1005-1008

44. Jobe A, Ikegami M, Jacobs H, Jones S, Conaway D 1983 Permeability of premature lamb lungs to protein and the effect of surfactant on that permeability. J Appl Physiol 55:169-176 